\title{
Assessment of Outcomes of Ileostomy Closure versus Colostomy Closure
}

Ali Helmy El-Shewy, Amr Ahmed Ibrahim, Yasser Ali Orban, Bassem Saeed Elgabry

Department of General and GIT Surgery, Faculty of Medicine, Zagazig University, Egypt

Corresponding Author: Bassem Saeed Elgabry, Mail: bassem.elgabry74@gmail.com

\begin{abstract}
Background: Small-bowel ostomies and large-bowel ostomies are two subtypes of intestinal ostomies based on the portion of the intestine that is exposed above the skin. Protecting the anastomosis from infection and keeping the peritoneum clean are critical functions of ileostomy and colostomy. Objective: to evaluate short term outcome of ileostomy and colostomy closures to recognize which procedure is better for diversion based on the outcomes of the stoma reversal.

Methods: Two groups of 32 patients having a colostomy or an ileostomy in Zagazig University Hospitals underwent a clinical comparison of the outcomes of stoma closure. 16 patients in Group 1 had an ileostomy for reversal. Those in Group 2 who had a temporary colostomy for reversal included 10 patients with Hartmann procedure and 6 patients with simple loop stoma. During the first month, patients were seen at the outpatient clinic once a week, then once a
\end{abstract} month for the next five months.

Results: As regard intraoperative complications: Amount of blood loss was higher among Hartmann's group (112 $\pm 18 \mathrm{ml}$ ) due to severe adhesions during laparotomy compared to ileostomy group $(89 \pm 16 \mathrm{ml})$ and loop colostomy group (98 $\pm 16 \mathrm{ml})$. In terms of intraoperative blood loss, there was no statistically significant difference between ileostomy and loop colostomy, although there was a statistically significant difference between ileostomy and the Hartman procedure. In the ileostomy group, postoperative problems such as wound infection, anastomotic leakage, ileus, and intraabdominal collection were less common and more easily controlled.

Conclusion: Ileostomy closure is superior to colostomy closure as simple closure with small circumferential incision was easier than colostomy which need exploration in most cases.

Keywords: Colostomy, Ileostomy, Intestinal ostomies

\section{INTRODUCTION}

Distal bowel anastomosis healing and blockage relief can be achieved by diverting the fecal stream away from the anastomosis via a stoma ${ }^{(\mathbf{1})}$. An intestine stoma is a hole in the abdominal wall that allows the intestines to pass through. Depending on the pathology and the requirement for construction, the stoma can be either a loop or an end ${ }^{(2)}$.

There are two main types of intestinal ostomies: small- and large-gut ostomies, which are divided into loop ostomies and end ostomies, respectively, based on the number of openings found in the bowel. Ileostomies are more commonly performed on the right side of the abdomen, while colostomies are more commonly performed on the left ${ }^{(3)}$.

Preoperative education, counselling, and ostomy site selection should be performed whenever possible by the surgeon and skilled ostomy nurse specialist in order to allay these fears in patients who require an ostomy due to misconceptions and fears about social acceptance, sexuality, and financial burden (4). By helping patients adjust to the considerable lifestyle adjustments that come with a stoma, preoperative counselling enhances their quality of life after the procedure. Additionally, it has been linked to a shorter hospital stay and fewer stoma-related postoperative problems ${ }^{(5)}$.

For stoma closure, there were no established guidelines. The idea of having to wear a stoma is distressing to many patients, and many are eager to get it removed as soon as possible. As a result, the stoma is eagerly anticipated by both surgeons and patients ${ }^{(6,7)}$. As long as the underlying problem has been treated, recovery has taken place and adhesions have softened, the ostomy reversal can be delayed for up to three months. A functional end-to-end anastomosis can be created by first releasing the stoma from the abdominal wall circumferentially, and then performing an ostomy closure along this side of the wall ${ }^{(8)}$.

Several clinical reviews have described parameters that could influence the outcome of intestinal stoma closure as the surgeon's experience, type of the stoma, the timing of the operation, the patient's age, etiology of the disease and coexistent medical conditions ${ }^{\left({ }^{9}\right)}$.

We aimed in this work to evaluate short term outcome of ileostomy and colostomy closures to recognize which procedure is better for diversion based on the outcomes of the stoma reversal.

\section{SUBJECTS AND METHODS}

From February 2020 to February 2021, at Zagazig University Hospitals we compared the outcomes of 32 ileostomy and colostomy patients who had been admitted for stoma closure in a clinical comparative study.

\section{Ethical considerations:}

All participants signed informed consent forms and the study was approved from Zagazig University's Research Ethics Committee, the study

This article is an open access article distributed under the terms and conditions of the Creative Commons Attribution (CC BY-SA) license (http://creativecommons.org/licenses/by/4.0/) 
was allowed with number (ZU-IRB\#6229). We followed the World Medical Association's ethical code for human experimentation, the Helsinki Declaration.

Inclusion criteria: All patients aged $>18$ years old with ileostomy or colostomy scheduled for stoma closure.

Exclusion criteria: Patients< 18 years old, complicated stoma, contraindications for stoma reversal, on immunosuppressive drugs or lost patient during the follow up.

\section{Two groups of patients were categorized:}

Group 1: Ileostomy group included 16 patients (100\%) with simple loop stoma.

Group 2: Colostomy group included 10 patients (62.5) with Hartmann procedure, 6 patients (37.5) with simple loop stoma.

This is what all of the participants in this research had to go through:

1. A thorough history and physical examination were performed.

2. Routine laboratory investigations $(\mathrm{CBC}$, Coagulation profile (PT, PTT and INR), LFTs, KFTs, Random blood glucose level and viral markers (HBV, HCV and HIV).

3. Radiological investigations:

- Pelvi-abdominal ultrasound to exclude any collection.

- Distal loopogram for all cases to detect if there was anastomotic leakage in the primary anastomosis and to exclude any distal obstruction.

- Metastatic work up in cases of malignancy including CT scan of pelvis and abdomen using contrast in malignant cases.

- ECG and echocardiography in cardiac patients or in patients $>40$ years old.

- Colonoscopic examination for all cases with rectal cancer.

All operations were performed under general anesthesia by a single surgeon.

\section{Surgical technique:}

The procedure for ileostomy closure: Approximately 2-3 $\mathrm{mm}$ of skin around the ileostomy was cut away during the procedure. In order to remove the surrounding tissues, both the proximal and distal limbs were dissected down to the peritoneal cavity. Proximal and distal bowel movement. Scissors were used to cut the planes apart. To avoid intestinal damage, cauterization was administered with extreme caution. The stoma's edges were trimmed. A side-to-side or end-to-end anastomosis was subsequently performed to complete the ileostomy, depending on the patient's preference. Continual handsewn anastomosis was carried out.

\section{The procedure for colostomy closure:}

Closure of loop colostomy: Incision around the colostomy was made on the skin. The adhesions in the subcutaneous tissue were dissected with sharp dissection to provide traction. Deepening the incision allowed access to the peritoneum, which is where the colostomy stoma is removed. The stoma's margins were trimmed, and the proximal limb of the colon was cut off. Any adhesions were divided. Stapling devices or handsewn anastomosis were used to perform anastomosis. Absorbable suture (PDS 4.0 or Vicryl 3.0) was used in a continuous, full-thickness way for the first seromuscular layer, followed by interrupted sutures for the second.

A drain was inserted into the abdomen. Polydioxanone (PDS) was used to seal the abdominal wall with continuous sutures. A subcutaneous drain was inserted after the primary skin closure was completed with 3-0 polypropylene interrupted sutures.

\section{Reversal of Hartmann's procedure:}

Laparotomy incisions were made. It was necessary to locate and mobilise the rectum's stump. A Foley catheter was used to inflate the urinay bladder with $300 \mathrm{~mL}$ of saline to aid in identifying the bladder and safely dissecting the rectal stump. A thorough examination of the bowel was performed once the stump was dislodged. The colostomy was deployed once it was determined that reconstruction could proceed. A 2-3 mm incision was made around the mucocutaneous junction on the skin. It was then possible to perform an anastomosis using either a stapling equipment or a handsewn method, depending on the patient's preference for the procedure. In both groups, considerable blood loss, adhesions, and damage to the colon were reported as intraoperative consequences.

\section{Postoperative follow up:}

Patients were followed up regularly in outpatient clinic once a week during the first month then once a month for the next 5 months 


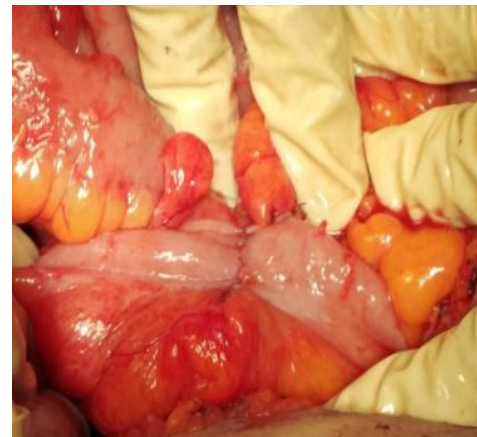

(A)

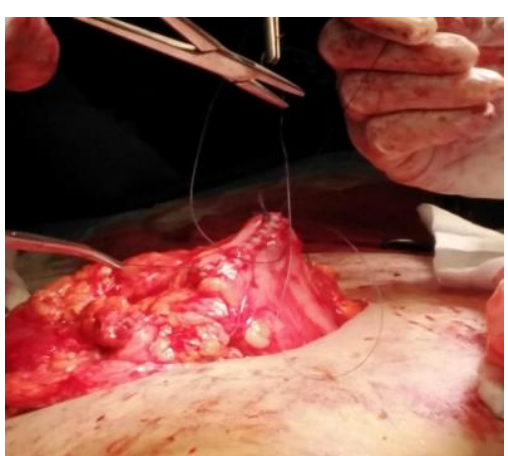

(B)

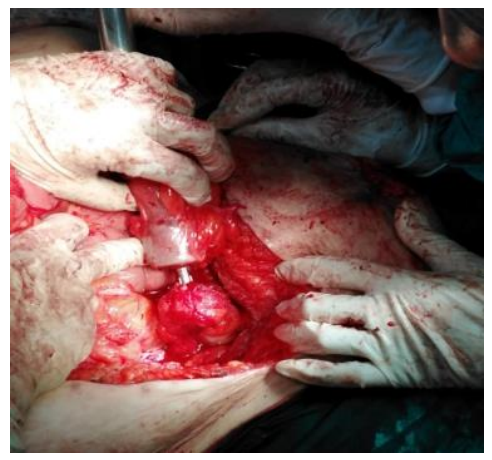

(C)

Figure (1): A) shows ileostomy closure using handsewn anastomosis, B) shows loop colostomy closure using handsewn anastomosis, C) shown Hartmann's closure by stapling device.

Wound infection was detected by unexplained fever and chills with redness of the skin around the wound, and was managed by partial opening of the wound, antibiotic administration and daily dressing. Ileus was detected by abdominal distension with delaying passage of flatus and stool for 72 hours. Intestinal sounds were not auditable by stethoscope. They were managed by (NPO - correction of serum electrolytes) until distension relieved. Abdominal collection was discovered that this patient had stomach pain and fever.

A CT scan of the abdomen with IV and oral contrast was performed and revealed the presence of a small abdominal collection. Management occurred by broad spectrum antibiotics and percutaneous drainage of collection. Abdominal pain, followed by fever and a rapid heartbeat, was the first sign. Intravenous and oral contrast were used in an abdominal computed tomography (CT) scan, which revealed small collections in the abdominal cavity and small perforations that allowed contrast to spill over into the abdominal cavity. It was minor leakage.
As the patient was stable, management occurred conservatively (NPO - TPN - broad spectrum antibiotics - correction of serum albumin and electrolytes and percutaneous drainage of collection).

\section{Statistical analysis}

IBM SPSS version 20.0 was used to analyse the data given into the computer. Armonk, NY: IBM Corporation. Qualitative data were presented in the form of percentages and numbers. For comparison and correlation studies, the Chi square test or Fisher's exact test was used. Quantitative variables were presented by means, standard deviation (SD), and range and were compared by the t-test (for parametric data).The significance of the findings was evaluated at a 5 percent value.

\section{RESULTS}

When it came to age, gender, comorbidities, and body mass index, there was no statistically significant difference between groups (Table 1).

Table (1): Comparison between the studied groups regarding demographic data, special habits, comorbidities, and BMI

\begin{tabular}{|l|c|c|c|}
\multirow{2}{*}{\multicolumn{1}{c|}{ Parameters }} & \multicolumn{2}{c|}{ Groups } \\
\cline { 2 - 3 } & Ileostomy group & Colostomy group & \multicolumn{1}{c|}{} \\
\cline { 2 - 3 } Age (year): & $\mathbf{N = 1 6}$ & $\mathbf{N = 1 6}$ & 0.754 \\
Mean \pm SD & $50.125 \pm 8.717$ & $49.063 \pm 10.253$ & \\
Range & $34-65$ & $25-61$ & 0.076 \\
\hline Gender: & & & \\
Female & $6(37.5)$ & $11(68.8)$ & \\
Male & $10(62.5)$ & $5(31.2)$ & 0.878 \\
\hline Diabetes mellitus (DM) & $2(12.5)$ & $3(18.75)$ & \\
DM and CKD & $1(6.2)$ & $0(0)$ & \\
DM and hypertension & $2(12.5)$ & $2(12.5)$ & \\
Hypertension & $3(18.75)$ & $3(18.8)$ & 0.449 \\
Smoking & $5(31.2)$ & $3(18.75)$ & \\
\hline BMI (kg/m $\mathbf{2}):$ & $27.75 \pm 2.62$ & $27.0 \pm 2.9$ & \\
Mean \pm SD & $23-32$ & $23-31$ & \\
Range & &
\end{tabular}


Cause and kind of stoma did not differ statistically significantly across the groups tested. Stoma formation and reversal times were not statistically different among the studied groups (Table 2).

Table (2): Comparison between the studied groups regarding preoperative assessment:

\begin{tabular}{|c|c|c|c|}
\hline \multirow{3}{*}{ Parameters } & \multicolumn{2}{|c|}{ Groups } & \multirow[t]{3}{*}{ P } \\
\hline & Ileostomy group & $\begin{array}{c}\text { Colostomy } \\
\text { group }\end{array}$ & \\
\hline & $\mathrm{N}=16$ & $\mathrm{~N}=16$ & \\
\hline $\begin{array}{l}\text { Type of stoma: } \\
\text { Hartmann's procedure } \\
\text { Simple loop }\end{array}$ & $\begin{array}{c}0(0) \\
16(100)\end{array}$ & $\begin{array}{c}10(62.5) \\
6(37.5)\end{array}$ & $<0.001^{*}$ \\
\hline $\begin{array}{l}\text { Cause of stoma: } \\
\text { Colorectal cancer } \\
\text { Diverticulitis coli }\end{array}$ & $\begin{array}{c}10(62.5) \\
6(37.5)\end{array}$ & $\begin{array}{l}7(43.8) \\
9(56.2)\end{array}$ & 0.288 \\
\hline $\begin{array}{l}\text { Time between stoma creation and } \\
\text { reversal } \\
\text { (in months): } \\
\text { Range } \\
\text { Mean } \pm \text { SD }\end{array}$ & $\begin{array}{c}3-7 \\
6.06 \pm 1.91\end{array}$ & $\begin{array}{c}3-9 \\
6.56 \pm 1.87\end{array}$ & 0.461 \\
\hline
\end{tabular}

**: statistically highly significant

\section{Operative data:}

The difference was significant between ileostomy and Hartman procedure as regard to blood loss intraoperatively. No patients had bladder injury during operation between the studied groups (Table 3).

Table (3): Comparison between the studied groups regarding operative data

\begin{tabular}{|c|c|c|c|c|}
\hline \multirow{4}{*}{ Parameters } & \multicolumn{3}{|c|}{ Groups } & \multirow[t]{4}{*}{$\mathrm{P}$} \\
\hline & \multirow{3}{*}{$\begin{array}{c}\begin{array}{c}\text { Ileostomy } \\
\text { group }\end{array} \\
\begin{array}{c}\mathrm{N}=16 \\
(\mathbf{1 0 0 \%})\end{array}\end{array}$} & \multicolumn{2}{|c|}{$\begin{array}{l}\text { Colostomy } \\
\text { group }\end{array}$} & \\
\hline & & $\begin{array}{c}\text { Loop } \\
\text { colostomy }\end{array}$ & $\begin{array}{l}\text { Hartmann's } \\
\text { procedure }\end{array}$ & \\
\hline & & $\begin{array}{c}\mathrm{N}=6 \\
(37.5 \%)\end{array}$ & $\begin{array}{c}\mathrm{N}=10 \\
(62.5 \%)\end{array}$ & \\
\hline $\begin{array}{l}\text { Operative time }(\mathbf{m i n}) \text { : } \\
\text { Range } \\
\text { Mean } \pm \text { SD }\end{array}$ & $\begin{array}{c}60-120 \\
45 \pm 28 \text { min }\end{array}$ & $\begin{array}{c}60-120 \\
45 \pm 28 \mathrm{~min}\end{array}$ & $\begin{array}{c}90-180 \\
55 \pm 60 \mathrm{~min}\end{array}$ & 0.056 \\
\hline Blood loss(cc) & $89 \pm 16 \mathrm{ml}$ & $98 \pm 16 \mathrm{ml}$ & $112 \pm 18 \mathrm{ml}$ & $\begin{array}{c}\text { P1 } 0.253 \\
\text { P2 } 0.14 \\
\text { P3 } 0.002 *\end{array}$ \\
\hline Serosal injury: & $0(0)$ & $0(0)$ & $2(13.3)$ & 0.097 \\
\hline Bladder injury: & $0(0)$ & $0(0)$ & $0(0)$ & 1 \\
\hline
\end{tabular}

*: Statistically significant, $\mathbf{P 1}$ the difference between ileostomy and loop colostomy, $\mathbf{2}$ the difference between

loop and Hartmann procedure, p3 the difference between ileostomy and Hartmann procedure Postoperative data:

After surgery, there was a statistically significant difference between the groups as regard overall incidence of complications.

There was significant difference between loop and Hartman colostomy regarding length of hospital stay (Table 4). 
Table (4): Comparison between the studied groups regarding postoperative complications

\begin{tabular}{|c|c|c|c|c|}
\hline \multirow[t]{3}{*}{ Parameters } & \multicolumn{3}{|c|}{ Groups } & \multirow[t]{3}{*}{$\mathrm{P}$} \\
\hline & \multirow{2}{*}{$\begin{array}{l}\text { Ileostomy } \\
\text { group } \\
\mathbf{N}=16(\%)\end{array}$} & \multicolumn{2}{|c|}{ Colostomy group } & \\
\hline & & $\begin{array}{c}\text { Loop } \\
\text { colostomy } \\
\mathrm{N}=6(37.5 \%)\end{array}$ & $\begin{array}{l}\text { Hartmann's } \\
\text { procedure } \\
\mathrm{N}=10(62.5 \%)\end{array}$ & \\
\hline \multirow{2}{*}{$\begin{array}{l}\text { Overall incidence of } \\
\text { complications: }\end{array}$} & \multicolumn{3}{|c|}{$10(55.6)$} & \multirow[b]{2}{*}{$0.033^{*}$} \\
\hline & $4(25)$ & $3(50)$ & $7(70)$ & \\
\hline Wound infection: & $2(12.5)$ & $2(33.3)$ & $3(30)$ & 0.796 \\
\hline Ileus: & $2(12.5)$ & $1(16.7)$ & $2(20)$ & 0.897 \\
\hline $\begin{array}{l}\text { Abdominal } \\
\text { Collection: }\end{array}$ & $0(0)$ & $0(0)$ & $1(10)$ & 0.721 \\
\hline Anastomotic leakage: & $0(0)$ & $0(0)$ & $2(20)$ & 0.496 \\
\hline $\begin{array}{l}\text { Hospital stay } \\
\text { (day): } \\
\text { Mean } \pm \text { SD } \\
\text { Range }\end{array}$ & $\begin{array}{c}4.03 \pm 2.08 \\
2-7\end{array}$ & $\begin{array}{c}4.55 \pm 2.2 \\
2-7\end{array}$ & $\begin{array}{c}6.91 \pm 3.1 \\
4-14 \\
\end{array}$ & $\begin{array}{l}\text { P10.055 } \\
\text { P2 } 0.096 \\
\text { P3 } 0.019\end{array}$ \\
\hline
\end{tabular}

*: Statistically significant, $\mathbf{P 1}$ the difference between ileostomy and loop colostomy, p2 the difference between loop and Hartmann procedure, p3 the difference between ileostomy and Hartmann procedure.

\section{DISCUSSION}

Ileostomy has been promoted by several authors because of its ease of construction and management, as well as their low complication rates ${ }^{(\mathbf{1 0})}$. While some advocate for the use of colostomy as a normal treatment, others believe that it has fewer consequences ${ }^{(\mathbf{1 1})}$. The death rate is generally lower when the intestines are reconnected ${ }^{\mathbf{( 1 2}}$. It's possible to reverse the position of one's stoma; however, it's possible to have serious complications (0\% to $9 \%$ ) and mild complications (4\% to $30 \%)^{(13)}$.

Ileostomy patients in this study were 50.125 years old, while colostomy patients were 49.063 years old. When it comes to their age, ileostomy and colonoscopy patients were not statistically different.

Bell and his colleges ${ }^{(14)}$ in their study about " $A$ comparison of complications associated with colostomy reversal versus ileostomy reversal" reported that, the demographic characteristics between ileostomy and colostomy group were similar. The mean age was 55 years (range 28 to 76) for the ileostomy group and was 56 years (range 40 to 74) for the colostomy group. So, there was no statistically significant difference between two groups as regard age, and this agree with our study.

There is statistically significant correlation between the occurrence of complications and age in our study, and this is in agreement with Fonseca $\boldsymbol{e t}$ al. ${ }^{(15)}$, who noted that, age has been regarded by some to greatly increase the incidence of problems. Despite this, some research found that it was not a risk factor at all. Older individuals typically have stomas due to cancer, which worsens their health and increases the risk of difficulties in the future. In general, patients who are younger and have had stomas established as a result of trauma will have less difficulties than older patients ${ }^{(15)}$.
In our study regarding bowel injury, two patients within Hartmann's group had small intestinal serosal injury during operation that was managed with interrupted sutures using Vicryl 4-0.

Postoperative wound infection was detected by unexplained fever and chills with redness of the skin around the wound, and was managed by opening of the wound, antibiotic administration and daily dressing. This finding is supported by Bell et al. ${ }^{(14)}$ who reported, wound infection in $1 / 20$ of patients of the ileostomy group while 6/20 patients in the colostomy group developed wound infection with statistically non- significant difference between the studied groups.

Two patients in Hartmann's group had an anastomotic leakage. This finding is supported by Bell et al. ${ }^{(14)}$ who reported that, anastomotic leakage not developed in patients of ileostomy group $(0 / 20)$ while $1 / 20$ of patients in the colostomy group developed leak with statistically non-significant difference between the studied groups.

Reversal of Hartmann's method is related with an anastomotic leakage rate of 30 percent and a mortality rate of 0 to 14.3 percent, according to a meta-analysis of 98 published publications by Salem and his colleagues ${ }^{(16)}$.

Our study results showed regarding ileus after closure of the stoma. Ileus occurred in two patients within ileostomy group, one patient within loop colostomy group and two patients within Hartmann's group. Bell and his colleges ${ }^{(\mathbf{1 4})}$ in their study reported that, postoperative ileus developed in one patient $(1 / 20)$ of ileostomy group while 3 patients $(3 / 20)$ in the colostomy group developed ileus with statistically non- significant difference between the studied groups.

According to our study there was no mortality in both groups and this is in agreement with Bell $\boldsymbol{e t}$ al. 
(14) who reported no postoperative deaths in 40 patients (20 in each group).

Our study showed that overall incidence of complications was $55.6 \%$ within colostomy group (70\% within Hartmann's group $+50 \%$ within loop colostomy group) versus $25 \%$ within ileostomy group.

The study done by Bell et al. ${ }^{(14)}$ reported that, reversal of colostomy is associated with significantly higher postoperative morbidity compared with ileostomy takedown. Complication rate was $26 \%$ in the ileostomy group and $71 \%$ in the colostomy group and this agrees with our study. Closing loop ileostomies, rather than loop colostomies, resulted in significantly fewer problems in a study of diverting loop stomas ${ }^{(\mathbf{1 7 )}}$. It is therefore important to select the appropriate type of ostomy during the initial surgical procedure (18). Luglio et al. (19) reported that, Ileostomy closure is associated with a low rate of serious complications in comparison with colostomy closure.

According to Chow et al. ${ }^{(12)}$ in retrospective research, there was a significant increase in the number of patients who were diagnosed with cancer. Morbidity rates of $17.3 \%$ and death rates of $0.4 \%$ are connected with ileostomy closure. A laparotomy is required by just 3.7 percent of patients who undergo ileostomy closure via peristomal incision.

\section{CONCLUSION}

We can conclude that ileostomy closure is superior to colostomy closure as simple closure with small circumferential incision was easier than colostomy which needed exploration in most cases. Intraoperative complications were less. Postoperative complications as wound infection, anastomotic leakage, ileus and intraabdominal collection were less and easily managed when occurred.

\section{Financial support and sponsorship: Nil. Conflict of interest: Nil.}

\section{REFERENCES}

1. Saunders R, Hemingway D (2005): Intestinal Stomas. Surg Int., 71:44-7.

2. Aziz A, Sheikh I, Jawaid M et al. (2009): Indications and complications of loop ileostomy. J Surg Pak., 14 (3):128-131.

3. Pine $\mathbf{J}$, Stevenson $\mathbf{L}$, On $\mathbf{J}$ (2020): Intestinal stomas. Surgery (Oxford), 38(1): 51-57.

4. Holzer B, Matzel K, Schiedeck T et al. (2005): Do geographic and educational factors influence the quality of life in rectal cancer patients with a permanent colostomy? Diseases of the Colon \& Rectum, 48(12): 2209-2216.

5. Nagle D (2013): Toward better understanding of readmissions for physiologic complications of ileostomy. Diseases of the Colon \& Rectum, 56(8): 933934.

6. Goldberg M, Aukett L, Carmel J et al. (2010): Management of the patient with a fecal ostomy: best practice guideline for clinicians. Journal of Wound Ostomy \& Continence Nursing, 37(6): 596- 598.

7. Gessler B, Haglind E, Angenete E (2012): Loop ileostomies in colorectal cancer patients-morbidity and risk factors for non reversal. Journal of Surgical Research, 178(2): 708-714.

8. Warren J, Beffa L, Carbonell A et al. (2018): Prophylactic placement of permanent synthetic mesh at the time of ostomy closure prevents formation of incisional hernias. Surgery, 163(4): 839- 846.

9. Memon Z, Qureshi S, Maher M (2009): Outcome of ileostomy closure: an audit in Surgical Ward 2. JPMC Karachi Pak J Surg., 25:230-234.

10. Klink C, Lioupis K, Binnebösel $M$ et al. (2011): Diversion stoma after colorectal surgery: loop colostomy or ileostomy?. International Journal of Colorectal Disease, 26(4): 431-436.

11. Hocevar B, Gray M (2008): Intestinal diversion (colostomy or ileostomy) in patients with severe bowel dysfunction following spinal cord injury. Journal of Wound Ostomy\& Continence Nursing, 35(2): 159-166.

12. Chow A, Tilney H, Paraskeva $P$ et al. (2009): The morbidity surrounding reversal of defunctioning ileostomies: a systematic review of 48 studies including 6,107 cases. International Journal of Colorectal Disease, 24(6): 711-723.

13. Hindenburg T, Rosenberg J (2010): Closing a temporary ileostomy within two weeks. Dan Med Bull., 57(6): 4157-63.

14. Bell C, Asolati M, Hamilton E et al. (2005): A comparison of complications associated with colostomy reversal versus ileostomy reversal. The American Journal of Surgery, 190(5): 717-720.

15. Fonseca A, Uramoto E, Santos-Rosa $O$ et al. (2017): Colostomy closure: risk factors for complications. $\mathrm{ABCD}$. Arquivos Brasileiros de Cirurgia Digestiva (São Paulo), 30: 231- 234.

16. Salem L, Anaya $D$, Roberts $K$ et al. (2005): Hartmann's colectomy and reversal in diverticulitis: a population-level assessment. Diseases of the Colon \& Rectum, 48(5): 988-995.

17. Geng H, Nasier D, Liu B et al. (2015): Meta- analysis of elective surgical complications related to defunctioning loop ileostomy compared with loop colostomy after low anterior resection for rectal carcinoma. The Annals of the Royal College of Surgeons of England, 97(7): 494-501.

18. Garber A, Hyman N, Osler T (2014): Complications of Hartmann takedown in a decade of preferred primary anastomosis. The American Journal of Surgery, 207(1): 60-64.

19. Luglio G, Pendlimari R, Holubar S et al. (2011): Loop ileostomy reversal after colon and rectal surgery: a single institutional 5-year experience in 944 patients. Archives of Surgery, 146(10): 1191-119. 